\title{
Olfactory Functions Scale with Circuit Restoration in a Rapidly Reversible Alzheimer's Disease Model
}

\author{
Ning Cheng, Li Bai, Elizabeth Steuer, and Leonardo Belluscio \\ Developmental Neural Plasticity Section, National Institute of Neurological Disorders and Stroke, National Institutes of Health, Bethesda, Maryland 20892
}

Neural circuits maintain a precise organization that is vital for normal brain functions and behaviors, but become disrupted during neurological disease. Understanding the connection between wiring accuracy and function to measure disease progression or recovery has been difficult because of the complexity of behavioral circuits. The olfactory system maintains well-defined neural connections that regenerate throughout life. We previously established a reversible in vivo model of Alzheimer's disease by overexpressing a humanized mutated amyloid precursor protein (hAPP) in olfactory sensory neurons (OSNs). Using this model, we currently show that hAPP is present in the OSN axons of mutant mice, which exhibit strong caspase 3 signal and reduced synaptic protein expression by 3 weeks of age. In the olfactory bulb, we show that glomerular structure is distorted and OSN axonal convergence is lost. In vivo functional imaging experiments further demonstrate disruption of the glomerular circuitry, and behavioral assays reveal that olfactory function is significantly impaired. Because OSNs regenerate, we also tested if the system could recover from hAPP-induced disruption. We found that after 1 or 3 weeks of shutting-off hAPP expression, the glomerular circuit was partially restored both anatomically and functionally, with behavioral deficits similarly reversed. Interestingly, the degree of functional recovery tracked directly with circuit restoration. Together, these data demonstrate that hAPP-induced circuit disruption and subsequent recovery can occur rapidly and that behavior can provide a measure of circuit organization. Thus, olfaction may serve as a useful biomarker to both follow disease progression and gauge potential recovery.

\section{Introduction}

Alzheimer's disease (AD) is the most common neurodegenerative disease in the world (World Alzheimer Report, 2012), producing neural loss throughout the brain. Understanding changes in circuitry related to the cognitive dysfunction in AD could provide critical insight for diagnosis and for tracking disease progression. Many studies have focused on analysis of cortical and hippocampal regions to elucidate the pathological processes associated with AD. For example, using animal models, it has been shown that increased levels of cortical $\mathrm{A} \beta$, the peptide thought to play a central role in the pathogenesis of $\mathrm{AD}$, lead to cognitive deficits, and that reducing $A \beta$ levels can improve behavioral phenotypes (Hardy and Selkoe, 2002). However, in the cortex, circuit organization exists at multiple levels (Callaway, 2002); and given its complexity and heterogeneity, precision is not always anatomically apparent (Stevens, 1998). Thus, it has been difficult to assess how wiring is changed in $\mathrm{AD}$ models and whether these changes correlate with specific functional deficits. In addition, a

\footnotetext{
Received Jan. 21, 2013; revised May 25, 2013; accepted June 17, 2013.

Author contributions: N.C. and L. Belluscio designed research; N.C., L. Bai, and E.S. performed research; N.C., E.S., and L. Belluscio analyzed data; N.C. and L. Belluscio wrote the paper.

This work was supported by the National Institute of Neurological Disorders and Stroke intramural program, project 1ZIANS003116-02. We thank Rini Singh and Amit Sethi for assistance and Dr. Susan Wray and members of the Belluscio laboratory for constructive comments.

The authors declare no competing financial interests.

Correspondence should be addressed to Dr. Leonardo Belluscio, National Institutes of Health, 35 Convent Drive, Bethesda, MD 20892. E-mail: bellusc@@inds.nih.gov.

DOI:10.1523/JNEUROSCI.0291-13.2013

Copyright $\odot 2013$ the authors $\quad 0270-6474 / 13 / 3312208-10 \$ 15.00 / 0$
}

lack of specific molecular markers for distinct neuronal classes adds to the challenge of identifying specific cell types that may be more vulnerable or resistant to disease.

Olfactory dysfunction occurs early in AD (Talamo et al., 1989; Bacon et al., 1998; Hawkes, 2003; Doty, 2009; Arnold et al., 2010) and the olfactory connections are well-defined to enable a clear evaluation of neural circuitry. In mammals, axons from olfactory sensory neurons (OSNs) expressing the same odorant receptor converge to stereotyped positions in the olfactory bulb (OB) forming glomeruli, which are organized into a precise anatomical map of odorant receptor identity, the glomerular map (Axel, 1995; Mombaerts, 2006; Cummings and Belluscio, 2008). This map provides an ideal framework to measure circuit organization and function of the OB. Moreover, because OSNs undergo constant turnover throughout life, repopulated by endogenous stem cells (Farbman, 1990; Calof et al., 1996; Cowan and Roskams, 2002), the olfactory system provides a unique in vivo means to examine the restoration of neural circuits after intervention and assess the related physiological and behavioral functions.

Previously, we established a reversible olfactory-based AD model in which mature OSNs can be rapidly and specifically induced to degenerate by overexpressing a humanized amyloid precursor protein (hAPP) that contains both the "Swedish" and "Indiana" familial mutations (Cheng et al., 2011b). Here we examined the downstream central effects of hAPP-induced neurodegeneration by evaluating the circuitry of the $\mathrm{OB}$ at both anatomical and functional levels. Using the glomerular map as an organizational framework, we found that hAPP-induced circuit disruption and subsequent recovery could occur rapidly in the 
olfactory system and that improvements in physiological and behavioral measures correlated directly with the degree of circuit restoration.

\section{Materials and Methods}

Olfactory marker protein (OMP)-tTA and tet $O-h A P P$ transgenic lines. We used the tetracycline-transactivation system (tet-off), allowing spatialtemporal control of transgene expression with the addition of doxycycline turning-off the promoter function (Gossen and Bujard, 1992; Lewandoski, 2001). TetO-hAPP line contains the hAPP transgene (humanized $\mathrm{A} \beta$-domain with familial $\mathrm{AD}$ mutations-KM570, 571NL "Swedish" and V617F "Indiana") (Jankowsky et al., 2005a). OMP-tTA line expresses the tetracycline transactivator in mature OSNs (Yu et al., 2004; Nguyen et al., 2007). OMP-tTA line was crossed with tetO-hAPP line to generate a line that selectively expresses hAPP in mature OSNs driven by the OMP promoter (OMP-hAPP line). Presumably, hAPP expression begins during embryonic development when the OMP promoter is activated (Nguyen et al., 2007). Genotyping was performed to recognize mutants containing both the $\mathrm{tTA}$ - and tetO-transgenes. Littermates containing no transgene, only tetO-hAPP transgene, or only OMP-tTA transgene were examined, and the results were indistinguishable. In most cases, littermates containing only tetO-hAPP transgene were selected as controls, except in the behavioral experiments where both tetO-hAPP and OMP-tTA mice were used as controls. Both sexes were used for experiments because all measured time points were before sexual maturity. All mice were mixed $(129 \times$ C57BL/6) background.

PCR primers were as follows: OMP-tTA, 5'-GGTTGCGTATTGGAAGATCAAGAGC-3'; 5' -GAGGAGCAGCTAGAAGAATGTCCC3'; tetO-hAPP, 5'-CCGAGATCTCTGAAGTGAAGATGGATG-3'; 5'-CCAAGCCTAGACCACGAGAATGC 3'.

Using olfactory reporter lines. The P2-IRES-tau-lacZ (-/-) (P2-ETL) line, in which neurons expressing the $\mathrm{P} 2$ olfactory receptor also express tau-lacZ, a fusion of the microtubule-associated protein $\tau$ and $\beta$-galactosidase, so both the P2 OSNs and their axons can be visualized (Mombaerts et al., 1996).

The M71-IRES-tau-lacZ (-/-) (M71-ETL) line, in which neurons expressing the M71 olfactory receptor also express tau-lacZ, allowing visualization of both the M71 OSNs and their axons (Vassalli et al., 2002).

The OMP-synapto-pHluorin (-/-) (OMP-SpH) line, in which a pHsensitive GFP variant is fused to VAMP-2, a synaptic vesicle protein. $\mathrm{SpH}$ is selectively expressed in the presynaptic terminals of OSNs in the glomeruli and provides a measure of synaptic vesicle fusion (Bozza et al., 2004). The strength of the signal depends on both synaptic release from individual axons and the degree of axonal convergence, thus reflecting functional organization of the glomerular map.

These reporter lines were crossed with OMP-hAPP mutants to generate compound transgenic lines that harbored both the OMP-tTA and tetO-hAPP transgenes as well as one copy of the reporter transgene. For example, the experimental group OMP-hAPP/P2-ETL $(+/-)$, and the control group tetO-hAPP/P2-ETL (+/-).

Turning off hAPP expression. Doxycycline-containing chow (Dox, 6 $\mathrm{g} / \mathrm{kg}, 0.5$-inch pellets, Bio-Serv) was fed to animals from 3-4 or 3-6 weeks of age, after mice had been weaned. Dox prevents the tTA-protein from binding to the tetO-sequence.

Immunohistochemistry. Fluorescence immunohistochemistry on $\mathrm{OB}$ sections was performed as previously described (Cummings and Belluscio, 2010). Primary antibodies included the following: hAPP, 1:1000 (6E10, Covance); OMP, 1:5000 (Wako); vesicular glutamate transporter 2 (VGlu2), 1:1000 (Millipore); cleaved-caspase3, 1:1000 (Cell Signaling Technology). Sections were examined using confocal microscopy (LSM510, Carl Zeiss).

Quantification of OMP- and VGlu2-positive areas. Images of OMP or VGlu2 immunohistochemical signal on four to six sample coronal sections were taken from each animal representing the anterior, middle, and posterior parts of the OB. The area was measured using the LSM Image Browser by outlining the OMP- or VGlu2-positive regions.

Whole-mount LacZ staining. Mouse heads were dissected to expose the medial surface of the olfactory epithelium and OB. For M71-ETL line, the skull around the OB was further removed to completely expose the OB. Tissue was subsequently fixed in $4 \%$ paraformaldehyde for $30 \mathrm{~min}$ on ice and rinsed sequentially with buffer A (PBS containing $2 \mathrm{mM} \mathrm{MgCl}_{2}$ ) and buffer $\mathrm{B}$ (PBS containing $2 \mathrm{mM} \mathrm{MgCl}_{2}, 0.01 \%$ sodium deoxycholate, and $0.02 \%$ Nonidet $\mathrm{P}-40$ ). Tissue was then incubated in the LacZ staining solution [buffer B with $5 \mathrm{~mm}$ potassium hexacyanoferrate (II) trihydrate, $5 \mathrm{~mm}$ potassium ferricyanide, and $0.2 \mathrm{mg} / \mathrm{ml} \mathrm{5-bromo-4-chloro-3-}$ indolyl- $\beta$-D-galactopyranoside] overnight at $32^{\circ} \mathrm{C}$. The reaction was stopped by adding $4 \%$ paraformaldehyde. Images of the whole-mount preparation, including both olfactory epithelium and bulb, were taken at both $4 \times$ and $10 \times$ using a SPOT digital camera (Diagnostic Instruments).

Cell counting. P2 and M71 neurons were counted manually from $10 \times$ images of the lacZ-stained olfactory epithelium. Each image was expanded to a size of $8.5 \times 11$ inches so that individual positive cells from turbinates I and II could be readily distinguished and counted. Individuals performing the counts were blind to the genotype of the animals.

In vivo SpH imaging. Mice were anesthetized using ketamine/xylazine (180 mg/kg and $4 \mathrm{mg} / \mathrm{kg}$ ) and maintained with isoflurane ( 1\% in $100 \%$ $\mathrm{O}_{2}$ ). A custom-modified intrinsic imaging system (Imager 3001 by Optical Imaging) attached to an epifluorescence microscope (Leica MZFL3) using an excitation wavelength of $488 \mathrm{~nm}$ and emission of $509 \mathrm{~nm}$ was used to image the dorsolateral surface of the OB through thinned skull. Before each experiment, the blood vessel pattern at the dorsal surface of each bulb was acquired for alignment purposes. Each animal was exposed to at least 6 odors: $1 \%$ ethyl butyrate, $2 \%(+)$ carvone, $2 \%$ hexanone, $2 \%$ tiglate, $1 \%$ propanal, and $1 \%$ butanal (v/v in mineral oil). Each trial consisted of an odor presentation and a no-odor presentation, and the sequence of the two was random. Each imaging trial lasted $10 \mathrm{~s}$, consisting of $3 \mathrm{~s}$ of baseline, $3 \mathrm{~s}$ of odor presentation, and $4 \mathrm{~s}$ after stimulus termination. SpH signal amplitude was analyzed using software WinMix (Optical Imaging) and presented as ratio images of signals concurrent with odor presentation to "no odor" signals: $\left(\right.$ signal $\left._{\text {odor }}-\operatorname{signal}_{\text {no odor }}\right) /$ signal $_{\text {no odor }}$ (Belluscio and Katz, 2001; Bozza et al., 2004). Quantification of possible active glomeruli was performed with Volocity (PerkinElmer), using an intensity threshold of 1.645 SD above the mean ( $>90 \%$ confidence interval) and size $\left(25-100 \mu \mathrm{m}^{2}\right)$ criteria, with manual validation based on the shape of the isolated glomeruli.

Olfactory behavior tests. Olfactory detection was assessed by the "buried-cookie" assay (Yang and Crawley, 2009). For two consecutive days before the test, animals were singly housed and a piece of cookie was placed in their cages and consumed by them. Before the test, mice were food-deprived for $24 \mathrm{~h}$. During the test, a mouse was placed in the test cage $(46 \mathrm{~cm} \mathrm{~L} \times 23.5 \mathrm{~cm} \mathrm{~W} \times 20 \mathrm{~cm} \mathrm{H})$ containing $5 \mathrm{~cm}$ of clean bedding for $10 \mathrm{~min}$ to acclimate to the cage. Then the mouse was removed from the test cage, and a piece of cookie was buried under the bedding on the bottom of the cage at a random location. The mouse was reintroduced to the test cage, and the time taken to retrieve the cookie was recorded. If mice failed to find the buried cookie after $10 \mathrm{~min}$ had elapsed, $600 \mathrm{~s}$ was recorded as the latency score. We observed that all animals were actively searching and digging when placed in the test cage, indicating that animals were sufficiently hungry and motivated to perform the test.

A two-bottle discrimination test was performed as previously described (Wysocki et al., 1977; Pourtier and Sicard, 1990; Griff and Reed, 1995). Although this test is referred to as a discrimination assay, the animals are tested for their ability to detect the presence of a single odor at progressively decreased concentration in their drinking water. Thus, this assay may also be considered a detection threshold test. Mice were individually housed without water but with restricted access to a saccharin-phthalic acid solution $\left(2.1 \times 10^{-2} \mathrm{M}\right.$ sodium saccharin and $10^{-3} \mathrm{M}$ phthalic acid) for $1 \mathrm{~h}$ twice a day for $2 \mathrm{~d}$ to ensure that they would commence drinking when the solution bottle was available. On day 3 , mice were given the saccharin-phthalic solution containing a $10^{-3}$ dilution of isovaleric acid, which has a distinctive odor, for 10 min. Immediately after this exposure, each mouse was removed from its cage, injected intraperitoneally with $15 \mu \mathrm{l} / \mathrm{g}$ body weight of $0.6 \mathrm{M} \mathrm{LiCl}$ to induce an aversive state, and then returned to a clean cage. Two hours later, each mouse was provided two bottles, one with the saccharin-phthalic acid solution and the other with the same solution plus isovaleric acid. For 
every $24 \mathrm{~h}$, the amount of fluid consumed was determined by weighing each bottle. Then the isovaleric acid concentration was reduced and the experiment continued, with the positions of the odor versus no-odor bottles in each cage reversed. A preference index was calculated as the amount of the isovaleric acid solution consumed divided by the total amount of liquid consumed for each mouse over the $24 \mathrm{~h}$ test period, for each isovaleric acid concentration.

Statistical analysis. Student's $t$ test was performed to test statistical significance, assuming two-tailed distribution and two-sample unequal variance. Values are mean $\pm S D$.

\section{Results \\ OSN axons degenerated and recovered in a hAPP-dependent manner}

OMP-hAPP transgenic mice specifically overexpress hAPP in mature OSNs under the control of the OMP promoter. This line established a model that revealed widespread OSN apoptosis by 3 weeks of age (Cheng et al., 2011b). Here we examined the axonal projection of OSNs in the OB of 3-week-old mutant mice and controls. Using nuclear staining, we found that the overall structure of the $\mathrm{OB}$ was altered in the mutant animals and that the size of the OB was clearly reduced. We also noted that the outer nerve layer and the glomerular layer were much thinner in the mutant animals, and there was a massive loss of glomeruli compared with controls (Fig. $1 A, B$ ). Furthermore, hAPP signal and cleaved-caspase 3 signal were readily detectable in the outer nerve layer, which is composed primarily of OSN axons (Fig $1 B$ ). This rapid and large-scale axonal degeneration is consistent with the OSN loss observed in the olfactory epithelium (Cheng et al., 2011b).

We previously showed that, when the OMP-hAPP mutant mice were fed Dox-containing chow from 3 to 4 weeks of age, hAPP expression was effectively turned off in the olfactory epithelium (Cheng et al., 2011b). In this study, we observed the same reduction in hAPP expression in OSN axons and also found that cleaved-caspase 3 signal in the outer nerve layer was dramatically reduced (Fig $1 B$ ). The observation that axonal degeneration did not persist after the shutdown of hAPP expression was consistent with a cell-autonomous hAPP effect. As a consequence of turning off hAPP expression, both the outer nerve layer and the glomerular layer were restored, although the glomeruli as delineated by periglomerular cell nuclei appeared disorganized compared with those in the tetO-hAPP control mice. Because earlier studies showed that 1 week of Dox administration was insufficient to rescue the majority of mature OSNs that already expressed hAPP (Cheng et al., 2011b), and OSNs continuously turn over (Farbman, 1990; Calof et al., 1996; Cowan and Roskams, 2002), these data suggest that the rapid recovery of the outer nerve layer and the glomerular layer is largely the result of axons from newly generated OSNs.

To directly visualize axonal innervation of the OB by mature OSNs, we performed immunohistochemical staining for OMP, a mature OSN marker found in OSN axons and their terminals (Hartman and Margolis, 1975). Results confirmed that there were far fewer OSN axons and glomeruli in the OMP-hAPP mutant animals compared with controls. The stark contrast with the well-formed outer nerve and glomerular layers in the control animals also confirmed the wiring disruption implicated by the nuclear staining (Fig 2A). Synaptic connectivity of OSNs was examined by staining for VGlu2, which is a relatively specific marker for OSN axon terminals in the OB (Gabellec et al., 2007). We noted a clear reduction in VGlu2 signal in the mutant animals compared with controls, further demonstrating a loss in OSN synaptic input (Fig 2A).
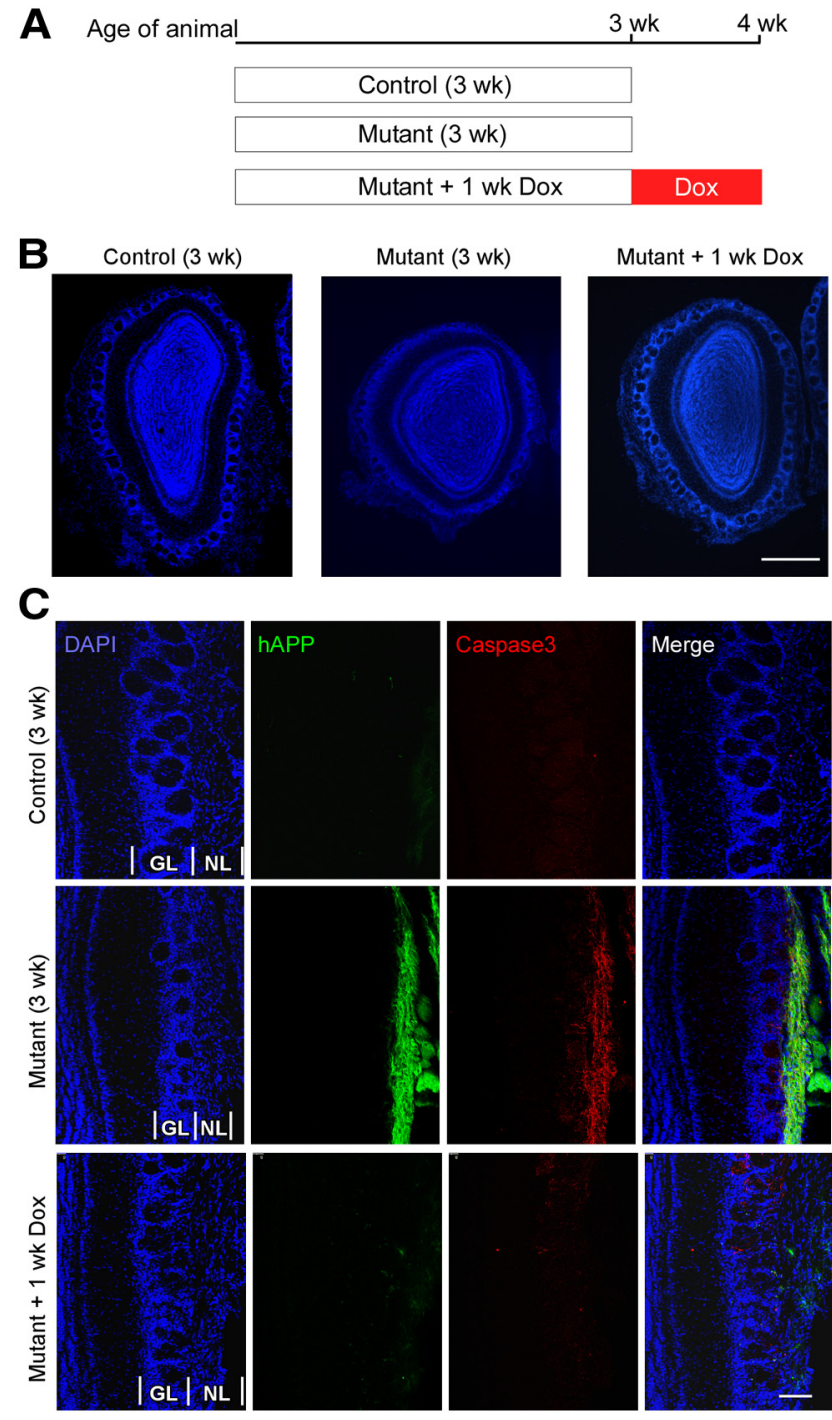

Figure 1. hAPP-dependent degeneration of OSN axons. $\boldsymbol{A}$, Diagram of experimental time course for different groups of animals. $\boldsymbol{B}$, Low-magnification images of DAPI nuclear staining on OB sections from 3-week-old tet0-hAPP control (left), 3-week-old OMP-hAPP mutant (middle), and mutant fed on Dox chow from 3 to 4 weeks of age (right). Compared with the control, glomeruli in the mutant were much smaller or absent. After Dox administration, the glomerular layer in the mutant partially recovered. Scale bar, $0.5 \mathrm{~mm}$. C, Higher-magnification images of $O B$ sections from the three groups of animals. Top row, control; middle row, mutant; bottom row, Dox-administered mutant. First column, DAPI nuclear signal; second column, hAPP immunohistochemical signal; third column, cleaved-caspase3 immunohistochemical signal; last column, merged image of the previous three channels. Strong cleaved-caspase3 signal was observed in OSN axons overexpressing hAPP. After Dox administration, hAPP expression was turned off and cleaved-caspase3 signal was much reduced. The glomerular layer appeared wider but was disorganized compared with that in the control. NL, Nerve layer; GL, glomerular layer. Scale bar, $100 \mu \mathrm{m}$.

To determine the extent to which axonal connectivity could be restored after turning off hAPP, we evaluated mutant animals after 1 week of Dox administration. We observed a striking increase in OMP-positive axons throughout the outer nerve layer and a rapid return of glomeruli filled with both OMP- and VGlu2-positive axon terminals in the Dox-treated mice (Fig 2A). Quantification of these changes confirmed that there was indeed a significant reduction in both OMP- and VGlu2-positive areas in the mutant animals compared with controls $(p=0.008$ and $p=$ 0.007 for OMP and VGlu2, respectively) and that both measures returned to control levels after 1 week of Dox administration (Fig 

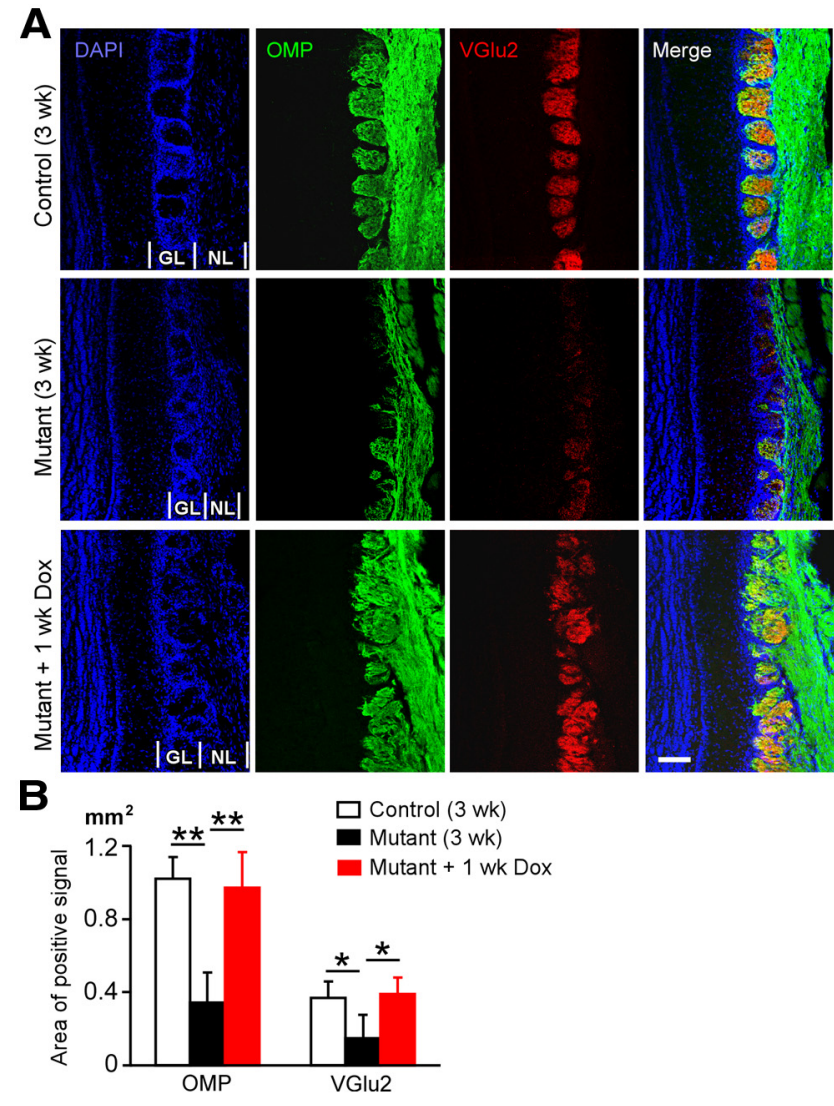

Figure 2. Disruption and recovery of OSN axonal connectivity. $A$, Images of $O B$ sections from three groups of animals: 3 -week-old tet0-hAPP control (top row), 3-week-old 0MP-hAPP mutant (middle row), and mutant fed on Dox chow from 3 to 4 weeks of age (bottom row). First column, DAPI nuclear signal; second column, OMP immunohistochemical signal; third column, VGlu2 immunohistochemical signal; last column, merged image of the previous three channels. Both OMP and VGlu2 expression was much reduced in the mutant animal. After 1 week of Dox administration, their expression was restored, but the glomerular structure was still disorganized. Scale bar, $100 \mu \mathrm{m}$. B, Quantification of OMP- and VGlu2-positive areas in OB sections from the three groups of animals. OMP-positive areas (mean \pm SD): control, $1.02 \pm 0.12 \mathrm{~mm}^{2}$, $n=4$; mutant, $0.32 \pm 0.16 \mathrm{~mm}^{2}, n=5$; and mutant Dox-administered for 1 week, $0.96 \pm$ $0.20 \mathrm{~mm}^{2}, n=5$. VGlu2-positive areas: control, $0.37 \pm 0.09 \mathrm{~mm}^{2}, n=4$; mutant, $0.13 \pm$ $0.12 \mathrm{~mm}^{2}, n=7$; and mutant Dox-administered for 1 week, $0.38 \pm 0.09 \mathrm{~mm}^{2}, n=5 .{ }^{*} p<$ $0.05 .{ }^{* *} p<0.001$.

$2 B)$. Interestingly, the restored glomeruli appeared less organized than those in controls, consistent with the nuclear staining and possibly indicating incomplete circuit restoration or mis-wiring.

\section{Differential restoration of OSN numbers and axonal convergence after hAPP shut-down}

Next, we sought to assess hAPP-induced disruption and subsequent recovery of glomerular wiring by specific input from different populations of OSNs. OSNs expressing the same odorant receptor project their axons to a pair of glomeruli in each $\mathrm{OB}$ to form the glomerular map (Axel, 1995; Mombaerts, 2006), which provides a clear anatomical indicator for measuring wiring accuracy within a specific circuit. Whole-mount LacZ staining of control animals that carry one copy of the P2-IRES-taulacZ (P2-ETL) reporter allele showed the numerous P2 neurons that resided in the olfactory epithelium. This preparation also allowed the visualization of $\mathrm{P} 2$ axons as they projected to the $\mathrm{OB}$ to form the medial P2 glomerulus (Fig. 3A). By comparison, in the OMP-hAPP mutant animals, far fewer P2 neurons and axons were detected with no obvious P2 axonal conver-
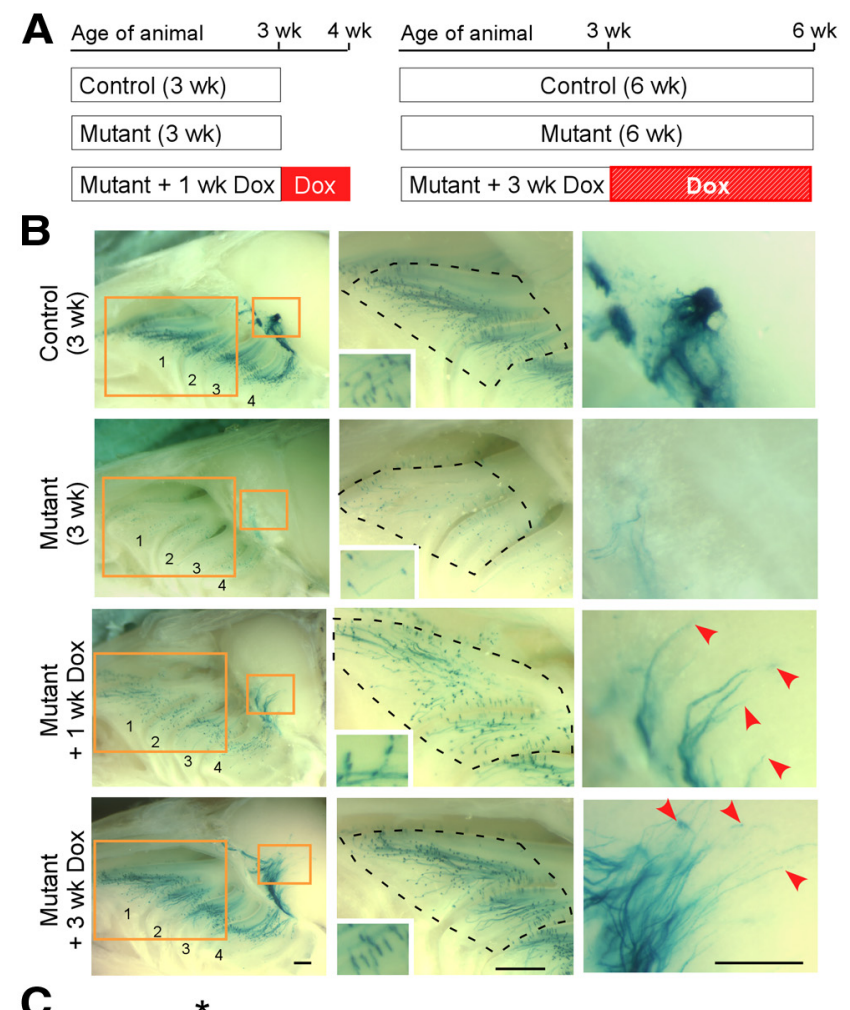

C

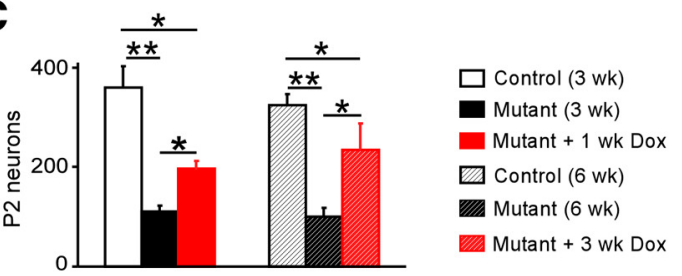

Figure 3. Partial restoration of $\mathrm{P} 2$ neurons after hAPP-induced degeneration. $A$, Diagram of experimental time course for different groups of animals. $\boldsymbol{B}$, Images of whole-mount X-gal staining of P2 neurons and their axons from four groups of animals: 3-week-old tet0-hAPP control (first row), 3-week-old OMP-hAPP mutant (second row), mutant fed on Dox chow from 3 to 4 weeks of age (third row), and mutant fed on Dox chow from 3 to 6 weeks of age (fourth row). Left column, Low-magnification images of $\mathrm{P} 2$ neurons and their axonal projections. Turbinates 1-4 were labeled. Boxed regions were shown in higher magnifications on the right. Middle column, Images of P2 neurons in the olfactory epithelium. Turbinates 1 and 2 where P2 neurons were counted were outlined by black dotted lines. Images at the lower left corners show individual neurons and their axons. Right column, Images of $\mathrm{P} 2$ axonal projections on the medial surface of the $O B$. Compared with the control, the mutant animal had far fewer P2 neurons in the epithelium and $\mathrm{P} 2$ axons innervating the $\mathrm{OB}$. After 1 week of Dox administration, more P2 neurons and their axons were observed in the mutant. However, the axons formed multiple sites of convergence (marked by red arrowheads), instead of a single glomerulus as in the control. After 3 weeks of Dox administration, even more P2 neurons and axons were observed, whereas the axons still projected to a wide area in the $0 \mathrm{~B}$. Scale bars, $400 \mu \mathrm{m} . \mathbf{C}$, Quantification of P2 neurons from six groups of animals (mean \pm SD): 3 -week-old control, $360 \pm 42, n=5$; 3-week-old mutant, $111 \pm 12, n=4$; mutant Dox-administered from 3 to 4 weeks of age, $199 \pm 19, n=4 ; 6$-week-old control, $324 \pm 23, n=4$; 6-week-old mutant, $101 \pm 17, n=6$; and mutant Dox-administered from 3 to 6 weeks of age, $235 \pm 52, n=5$. ${ }^{*} p<0.05 .{ }^{* *} p<0.001$.

gence in the $\mathrm{OB}$ (Fig. $3 A, B$ ). Because the olfactory system is capable of recovering axonal convergence after disruption (Gogos et al., 2000; Cummings and Belluscio, 2010; Cheng et al., 2011a), we next sought to determine whether hAPPinduced circuit degeneration could be restored. Interestingly, after just 1 week of Dox administration to the mutant mice from 3 to 4 weeks of age, we observed significantly more P2 neurons in the olfactory epithelium $(p=0.005)$, and more P2 
A
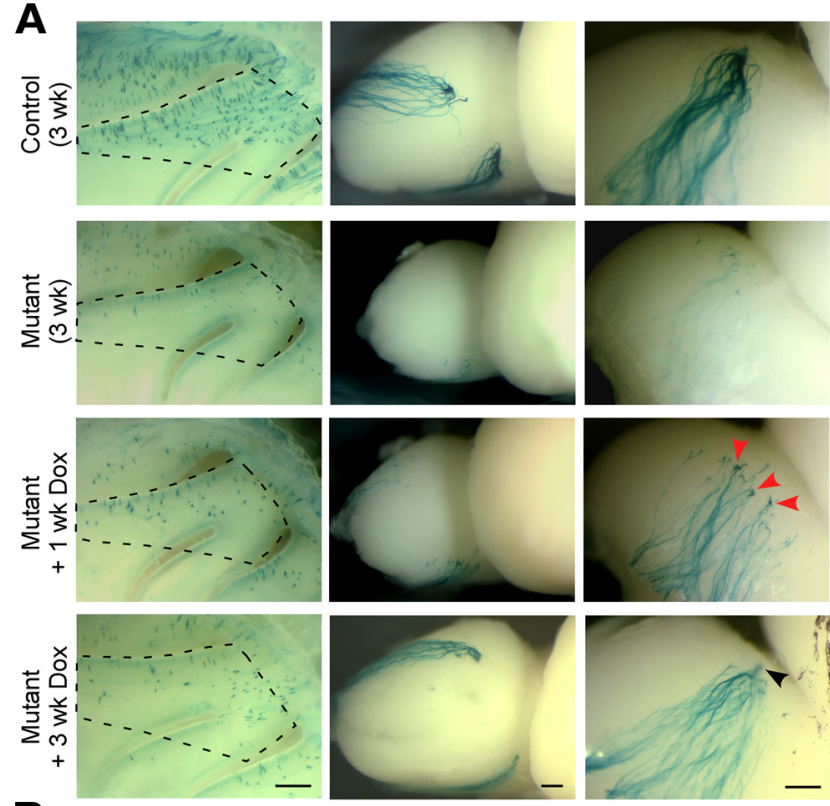

B
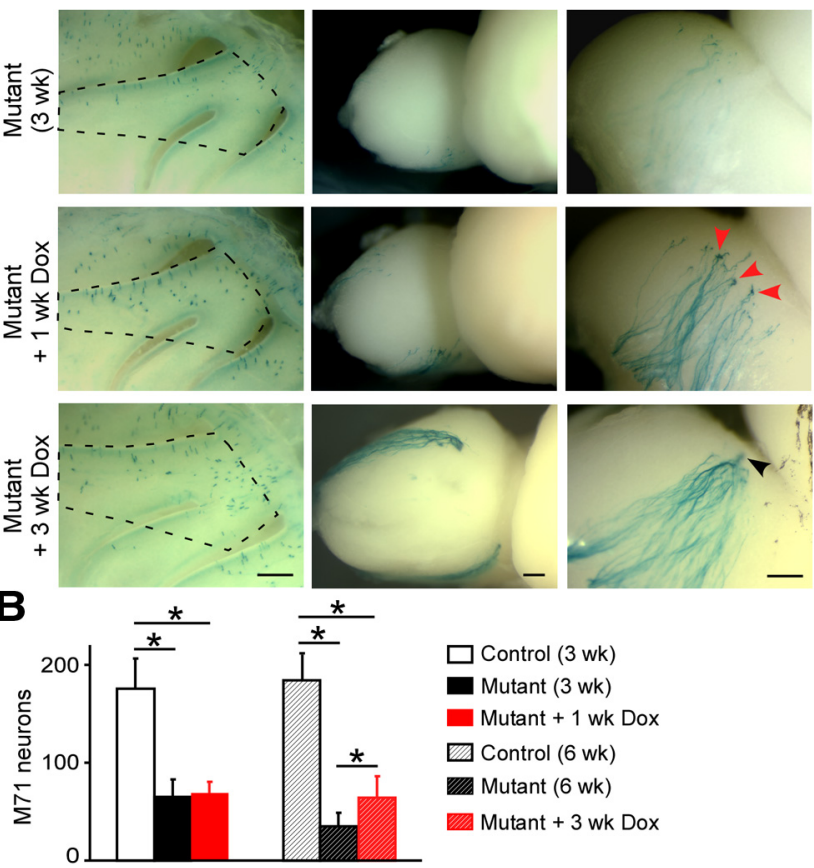

Figure 4. Disruption and recovery of the M71 OSNs. A, Images of whole-mount X-gal staining of M71 neurons and their axons from four groups of animals: 3-week-old tet0-hAPP control (first row), 3-week-old 0MP-hAPP mutant (second row), mutant fed on Dox chow from 3 to 4 weeks of age (third row), and mutant Dox-administered from 3 to 6 weeks of age (fourth row). Left column, Images of M71 neurons in the olfactory epithelium. Turbinates 1 and 2 where M71 neurons were counted were outlined by black dotted lines. Middle column, Images of M71 axon projections in the $\mathrm{OB}$. Right column, Higher-magnification images of M71 axonal projections on the medial side of the OB. Compared with the control, the mutant had far fewer M71 neurons in the epithelium and fewer M71 axons innervating the OB. After 1 week of Dox administration, M71 population in the epithelium of the mutant animal did not change, but more M71 axons were observed in the $O B$. The axons form multiple sites of convergence, as marked by red arrowheads, instead of a single glomerulus as in the control. After 3 weeks of Dox administration, M71 neurons increased in number compared with those in 6-week-old mutant without Dox administration; and in most cases, their axons converged into a single locus (marked by black arrowhead). Scale bars, $200 \mu \mathrm{m}$. B, Quantification of M71 neurons from six groups of animals (mean \pm SD): 3 -week-old control, $175 \pm 31, n=5$; 3-week-old mutant, $65 \pm 18$, $n=5$; mutant Dox-administered from 3 to 4 weeks of age, $69 \pm 11, n=5$; 6 -week-old control, $185 \pm 27, n=5 ; 6$-week-old mutant, $35 \pm 14, n=5$; and mutant Dox-administered from 3 to 6 weeks of age, $64 \pm 22, n=7 .{ }^{*} p<0.05$.

axons present in the $\mathrm{OB}$, although they failed to converge into a single glomerulus (Fig. $3 A, B$ ).

Despite the partial recovery observed after 1 week of Dox administration, the $\mathrm{P} 2$ population in the mutant animals was still significantly smaller than in controls $(p=0.002)$. To determine whether a longer recovery period could further restore the P2 population, we increased the recovery period to 3 weeks by maintaining the mutant mice on Dox-containing chow from 3 to 6 weeks of age. Results showed a clear scaling in OSN recovery with even more P2 neurons present after 3 weeks of Dox administration and more $\mathrm{P} 2$ axons visible in the $\mathrm{OB}$, whereas in mutant animals that did not receive Dox, the P2 population remained reduced (Fig. 3B).

We also examined M71-expressing OSNs in the mutant animals and found a significant decrease in their number (Fig. $4 A, B$; $p=0.002)$. However, after 1 week of Dox administration, there was no significant increase in this population $(p=0.708)$, but there were clearly more M71-axons observed in the OB (Fig. $4 A$, red arrows), suggesting that existing M71-neurons may be healthier. Assessment after 3 weeks of Dox administration showed that M71-OSNs were now significantly increased compared with mutants that did not receive Dox $(p=0.022)$ but still did not return to control levels. By comparison, the M71 axons were able to again converge and form one or two glomeruli in each half bulb in most cases (12 of 20 half bulbs, Fig. 4A, black arrowhead) with others showing varied degrees of restoration. Interestingly, when Dox was administered to mutant mice very early, from 0 to 3 weeks of age, both M71 and P2 OSNs showed greater recovery in terms of neuron numbers and axonal convergence (data not shown), consistent with the premise that earlier intervention is more effective.

Odor-induced activity was reduced but progressively restored with Dox administration

To assess the consequences of hAPP-induced OSN loss on OB function, animals were crossed with the OMP-SpH reporter line, which allowed us to perform in vivo functional imaging on both mutant and control animals. OMP-SpH is a knock-in mouse line that expresses Synapto-pHluorin $(\mathrm{SpH})$ under the control of the OMP promoter. Previous studies have shown that $\mathrm{SpH}$ is selectively expressed in the presynaptic terminals of mature OSNs and that changes in fluorescence report synaptic vesicle fusion (Bozza et al., 2004). Because $\mathrm{SpH}$ signals depend on synaptic release from individual axons, its intensity is partially determined by the degree of axonal convergence, which in turn also reflects the functional organization of the glomerular map. In control animals, robust $\mathrm{SpH}$ signals were observed on the dorsal surface of the $\mathrm{OB}$ when mice were exposed to different odors. By contrast, the OMP-hAPP mutant mice showed virtually no detectable focal signals when presented with the same array of odors (Fig. $5 A, B$ ), suggesting widespread loss of olfactory function.

After 1 week of Dox administration to the mutant mice from 3 to 4 weeks of age, modest odor-induced $\mathrm{SpH}$ signals were observed. For one of the six odors tested (butanal), there were significantly more glomeruli activated in the Dox-treated mutants compared with the untreated mutants ( $p=0.020$ ); however, the responses to other odors did not show significant recovery (Fig. $5 A, B)$. After 3 weeks of Dox administration, odor-induced signals were further restored in the mutant animals. There were significantly more glomeruli activated by four of the six odors (butanal, ethylbutyrate, carvone, and propanal) compared with mutant animals without Dox administration $(p=0.031, p=$ $0.029, p=0.033$, and $p=0.043$, respectively), and the numbers of activated glomeruli for all tested odors were no longer significantly different from controls (Fig. $5 A, B$ ). Notably, the signal peaks were still less discernible than those in controls, likely because of incomplete restoration of some glomeruli. Nonetheless, because axonal projections from P2 and M71 neurons also showed a graded recovery, with 3 weeks of Dox administration providing better anatomical restoration than 1 week, these data indicate that the functional organization of the glomerular map correlated directly with the anatomical organization at both stages of recovery.

\section{Behavior reveals impaired olfactory detection with differential recovery}

To further investigate the functional consequences of hAPPinduced disruption in the $\mathrm{OB}$ circuitry, we performed behavioral 
A
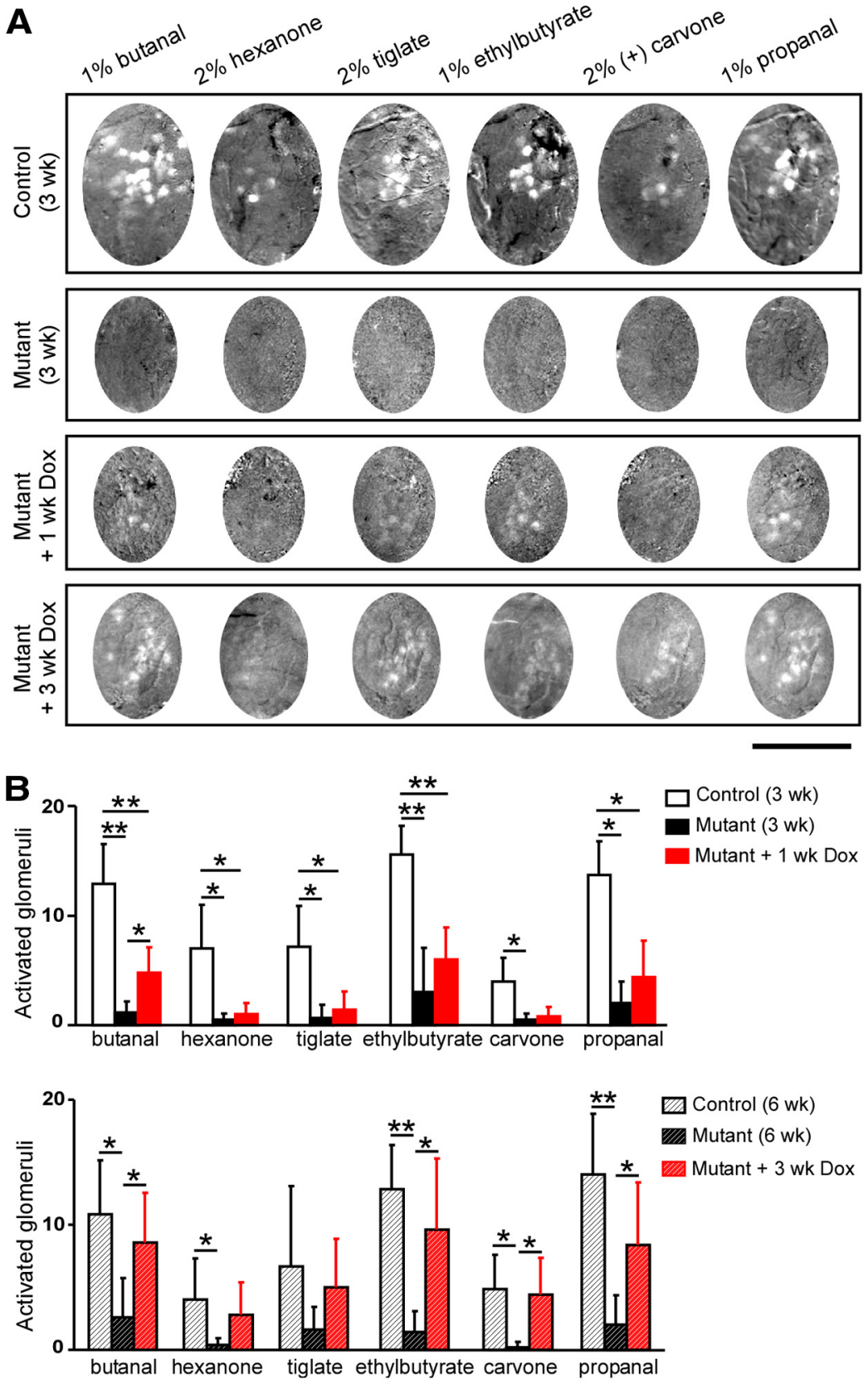

Figure 5. Loss of functional glomerular maps and their gradual restoration. $A$, Examples of odor-induced SpH signal from four groups of animals: 3-week-old tet0-hAPP control (first row), 3-week-old OMP-hAPP mutant (second row), mutant fed on Dox chow from 3 to 4 weeks of age (third row), and mutant Dox-administered from 3 to 6 weeks of age (last row). The ovals represent the areas where the signal could be clearly observed. Each column of signal was elicited by the odor shown on top. Robust signal was observed in the control across different odor stimuli, whereas little focal signal was detected in the mutant. After 1 week of Dox administration, more signal could be observed in the mutant, but it was from fewer glomeruli than that in the control. After 3 weeks of Dox administration, odor-induced SpH signal was further restored in the mutant, although generally it was still less robust than that in the control. Scale bar, $1 \mathrm{~mm}$. $\boldsymbol{B}$, Quantification of presumably glomeruli activated by different odors in one bulb (mean \pm SD). Top, Data from 3-week-old control and mutant, as well as mutant administered with Dox from 3 to 4 weeks of age. Butanal: control, $12.9 \pm 3.6, n=8$; mutant, $1.2 \pm 1.0, n=6$; and mutant +1 week Dox, $4.8 \pm 2.3, n=5$. Hexanone: control $7.0 \pm 4.0, n=7$; mutant, $0.5 \pm 0.6, n=6$; and mutant +1 week Dox, $1.0 \pm 1.0, n=5$. Tiglate: control, $7.1 \pm 3.8, n=7$; mutant, $0.7 \pm 1.2, n=6$; and mutant +1 week Dox, $1.4 \pm 1.7, n=5$. Ethylbutyrate: control, $15.6 \pm 2.6, n=7$; mutant, $3.0 \pm$ $4.1, n=5$; and mutant +1 week Dox, $6.0 \pm 2.9, n=5$. Carvone: control, $4.0 \pm 2.2, n=4$; mutant, $0.5 \pm 0.6, n=4$; and mutant +1 week Dox $, 0.8 \pm 0.8, n=5$. Propanal: control, $13.7 \pm 3.1, n=3 ;$ mutant, $2.0 \pm 2.0, n=4$; and mutant +1 week Dox, $4.4 \pm 3.3, n=5$. Bottom, Data from 6-week-old control $(n=6)$ and mutant $(n=5)$, as well as mutant administered with Dox from 3 to 6 weeks of age $(n=5)$. Butanal: control, $10.8 \pm 4.3$; mutant, $2.6 \pm 3.1$; and mutant +3 week Dox, $8.6 \pm 4.0$. Hexanone: control, $4.0 \pm 3.3$; mutant, $0.4 \pm 0.6$; and mutant +3 week Dox, $2.8 \pm 2.6$. Tiglate: control, $6.7 \pm 6.4$; mutant, $1.6 \pm$ 1.8; and mutant +3 week Dox, $5.0 \pm 3.9$. Ethylbutyrate: control, $12.8 \pm 3.5$; mutant, $1.4 \pm 1.7$; and mutant +3 week Dox, 9.6 \pm 5.7. Carvone: control, $4.8 \pm 2.8$; mutant, $0.2 \pm 0.5$; and mutant +3 week Dox, $4.4 \pm 3.0$. Propanal: control, $14 \pm 4.9$; mutant, $2.0 \pm 2.4$; and mutant +3 week Dox, $8.4 \pm 5.0 .{ }^{*} p<0.05$. ${ }^{* *} p<0.001$. testing. Olfactory detection of food was tested through a simple "buried-food" assay (Yang and Crawley, 2009). This test measures the time required for an animal to locate and retrieve a cookie buried under the mouse bedding. Although both tetO-hAPP and OMP-tTA control mice performed similarly in this task, it took OMP-hAPP mutant animals a significantly longer time to find the cookie (Fig. $6 A ; p=4.4 \times 10^{-9}$ and $5.7 \times 10^{-9} \mathrm{com}^{-}$ pared with tetO-hAPP and OMP-tTA, respectively).

We next examined olfactory detection threshold using an avoidance assay in which the simple odorant isovaleric acid (iVA) is added to the drinking water and becomes an aversive stimulus associated with an LiCl injection (Wysocki et al., 1977; Pourtier and Sicard, 1990; Griff and Reed, 1995). Conditioned animals are subsequently presented with a choice assay of either drinking plain water (noodor) or water containing iVA (odorwater) at decreasing concentrations. The results are reported as a preference index for the odor-water of each group of animals calculated as the amount of the odorwater consumed divided by the total amount of liquid consumed (both odorwater and no-odor water). Data showed that conditioned control animals preferred the no-odor water to the odorwater with iVA at dilutions of $10^{-3}, 10^{-4}$, and $10^{-5}$. However, when iVA was diluted to $10^{-7}$, the control animals failed to detect it shown by a preference index near $50 \%$. By contrast, the preference of the mutant animals for the odor-water was significantly higher than that of controls at $10^{-3}, 10^{-4}$, and $10^{-5}$ iVA dilutions (Fig. $6 B ; p=0.006, p=0.004$, and $p=0.004$, respectively), demonstrating their decreased ability to detect the odor at all concentrations. Notably, even the mutant animals showed less preference for the odor-water at $10^{-3}$ than at $10^{-7}$ dilution of iVA $(p=0.008)$, indicating that the behavioral dysfunction was most likely the result of a reduced ability to detect the odor rather than a learning deficiency. Thus, the defects in detection of both food and monomolecular odors were clear and consistent with the widespread disruption of the glomerular map circuitry shown earlier.

To assess the functional restoration of the olfactory circuitry, we next tested animals that were fed Dox-containing chow using these same behavioral assays. We found that, after just 1 week of Dox administration, there was no longer a significant difference between the performance 

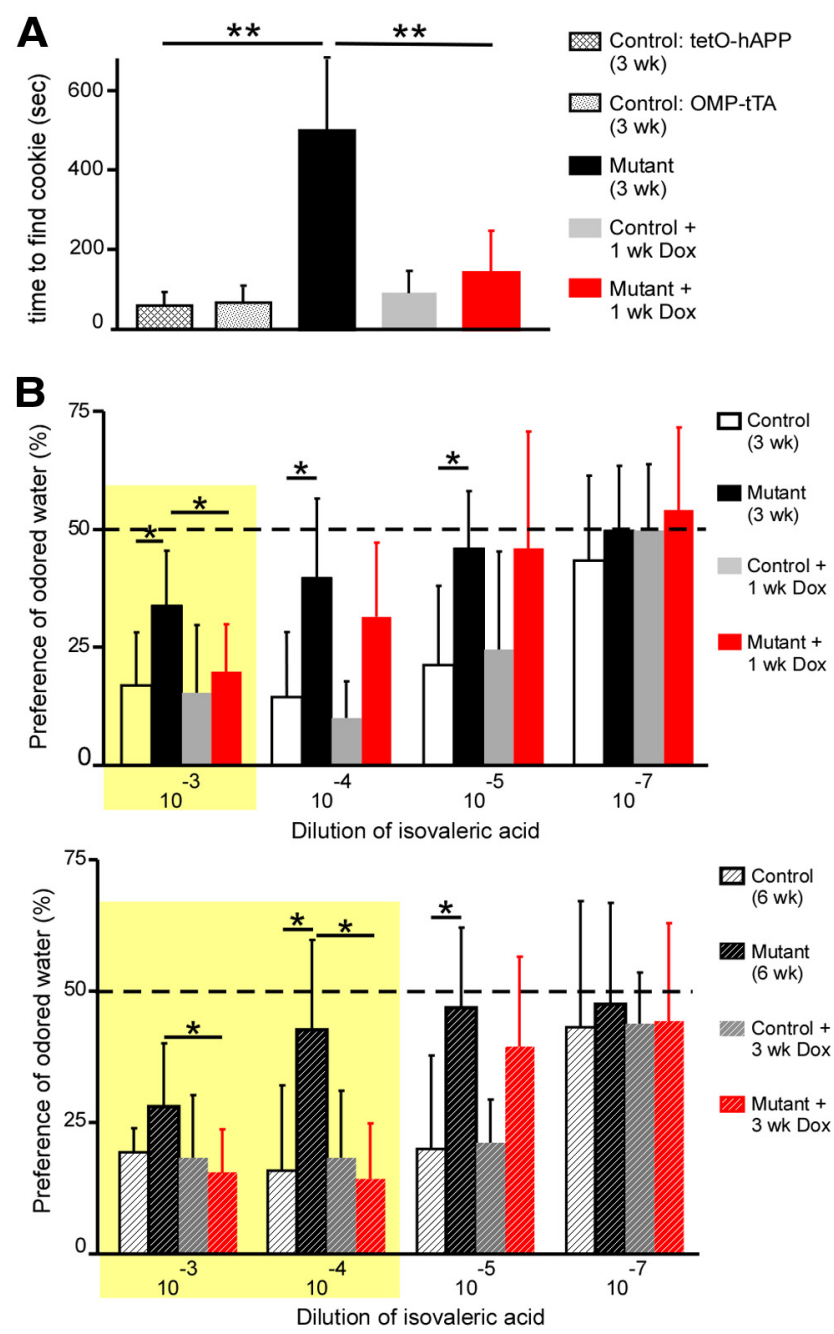

Figure 6. Impairment and recovery of olfactory-based behaviors. Olfactory detection of food odor and monomolecular odorants were significantly impaired in the mutant animals, and while detection of food odor recovered with 1 week of Dox administration, detection of monomolecular odorants showed more gradual improvement. $A$, Olfactory detection of food odor. The time for the mutant animals to find the cookie buried under mouse bedding was significantly longer than that for the controls (both tet0-hAPP and OMP-tTA groups). After 1 week of Dox administration, the time for the mutant mice to find the cookie was significantly shorter compared with nonadministered mutant animals and was not significantly different from the controls. The OMP-tTA control group performed very similarly to the tet0-hAPP control group. Time to find the cookie (mean \pm SD): tet0-hAPP control, $58 \pm 30 \mathrm{~s}, n=8 ;$ OMP-tTA control, $65 \pm 40 \mathrm{~s}, n=5 ; 0 \mathrm{MP}$-hAPP mutant, $498 \pm 179 \mathrm{~s}, n=18$; control (including both tet0-hAPP and OMP-tTA groups) +1 week Dox, $81 \pm 59 s, n=8$; and mutant +1 week Dox, $143 \pm$ $106 s, n=13$. B , Avoidance assay using a monomolecular odor. The preference shown on the $y$-axis is the ratio of iVA solution consumed to the total solution consumed expressed as a percentage. The mutant animals showed significantly greater preference toward iVA solution than the controls (including both tet0-hAPP and OMP-tTA groups) at $10^{-3}, 10^{-4}$, and $10^{-5}$ dilutions of iVA. After 1 week of Dox administration, the mutant animals showed significantly less preference at $10^{-3}$ dilution of iVA compared with nonadministered mutant (yellow shaded region), but not at $10^{-4}$ or $10^{-5}$ dilutions. After 3 weeks of Dox administration, the mutant animals showed significantly less preference at $10^{-3}$ and $10^{-4}$ (yellow shaded region) but not $10^{-5}$ dilutions, compared with nonadministered mutant. Top, Preference of animals at 3-4 weeks of age (mean \pm SD). $10^{-3}$ dilution: control, $17 \pm 11 \%$; mutant, $34 \pm 12 \%$; control +1 week Dox, $15 \pm 14 \%$; and mutant +1 week Dox, $20 \pm 10 \% .10^{-4}$ dilution: control, $14 \pm 16 \%$; mutant, $40 \pm 17 \%$; control +1 week Dox, $10 \pm 8 \%$; and mutant +1 week Dox, $31 \pm 16 \% .10^{-5}$ dilution: control, $21 \pm 17 \%$; mutant, $46 \pm 12 \%$; control +1 week Dox, $25 \pm 21 \%$; and mutant +1 week Dox, $46 \pm 25 \% .10^{-7}$ dilution: control, $43 \pm 18 \%$; mutant, $50 \pm 14 \%$; control +1 week Dox, $50 \pm 14 \%$; and mutant +1 week Dox, $54 \pm 17 \%$. Control: $n=8$; mutant: $n=11$; control +1 week Dox: $n=9$; and mutant +1 week Dox: $n=$ 13. Bottom, Preference of animals at 6 weeks of age. $10^{-3}$ dilution: control, $20 \pm 4 \%$; mutant, $28 \pm$ 10\%; control + 3 week Dox, $18 \pm 12 \%$; and mutant +3 week Dox, $15 \pm 9 \% .10^{-4}$ dilution: of mutant and control animals in the buried-cookie assay ( $p=$ $0.101)$. The mutant animals also performed similarly to controls $(p=0.597)$ and significantly better than the mutant group without Dox administration $(p=0.007)$ in the avoidance assay at $10^{-3}$ dilution of iVA. However, at lower concentrations of iVA, their performance was still significantly worse than controls ( $p=$ 0.001 and $p=0.036$ for $10^{-4}$ and $10^{-5}$ dilutions, respectively), and was not significantly different from the mutant animals without Dox administration $\left(p=0.231\right.$ and $p=0.987$ for $10^{-4}$ and $10^{-5}$ dilutions, respectively), suggesting that they still had difficulty distinguishing the odor-water from the no-odor water at these concentrations. Interestingly, after 3 weeks of Dox administration, the mutant animals showed greater improvement, performing similarly to controls in the avoidance assay at $10^{-4} \mathrm{iVA}$ dilution $(p=0.324)$ and significantly better than the mutant mice without Dox administration $(p=0.0003)$. However, this improvement was not observed at the $10^{-5}$ dilution. Thus, after 1 week of recovery, the mutant animals were able to detect the cookie odor and relatively high concentration of iVA but remained impaired when trying to detect lower iVA concentrations. With an additional 2 weeks of recovery, there was further improvement in their behavioral performance, indicating that the restoration of olfactory function assessed through behavior directly scales with the circuit organization.

\section{Discussion}

$\mathrm{AD}$ is a widespread neurodegenerative disease with no effective treatment. Here, we took advantage of the precise organization and the regeneration ability of the olfactory system to model this disorder. We examined the organization of the olfactory bulb in 3-week-old mice after hAPP-induced OSN degeneration. We observed rapid and widespread disruption of olfactory circuitry that was reversible. Using anatomical, functional, and behavioral analysis, we also showed that the degree of circuit restoration tracked with the degree of functional recovery.

The pathology of $\mathrm{AD}$ is characterized by gross brain atrophy, the accumulation of extracellular $\mathrm{A} \beta$ plaques, intracellular neurofibrillary tangles, widespread synaptic loss, and neuronal death (Hardy and Selkoe, 2002). Transgenic mice overexpressing mutant APP have been useful in reproducing many AD-related phenotypes, including intraneuronal amyloid accumulation, extracellular plaques, synaptic loss, neuritic dystrophy, vasculopathy, and gliosis (Ashe and Zahs, 2010; Laferla and Green, 2012). Functionally, these models have also revealed alterations in synaptic current, aberrant network activity, and impairments of learning and memory (Palop and Mucke, 2010), all of which imply changes in the underlying circuitry. Unfortunately, these studies have largely focused on the pathology of cortical and hippocampal regions where wiring accuracy is difficult to assess.

Recently, studies have emerged that take advantage of the link between early olfactory dysfunction and AD. In the Tg2576 AD mouse model, network dysfunction has been observed in both the $\mathrm{OB}$ and the piriform cortex, and olfactory behavior starts to deteriorate at 6-7 months of age (Wesson et al., 2010, 2011). Other studies used the precise organization of the olfactory cir-

$\leftarrow$

control, $16 \pm 16 \%$; mutant, $43 \pm 17 \%$; control +3 week Dox, $18 \pm 13 \%$; and mutant +3 week Dox, $12 \pm 11 \%$. $10^{-5}$ dilution: control, $20 \pm 18 \%$; mutant, $47 \pm 15 \%$; control +3 week Dox, $21 \pm 8 \%$; and mutant +3 week Dox, $40 \pm 17 \% .10^{-7}$ dilution: control, $43 \pm 24 \%$; mutant, $48 \pm 19 \%$; control +3 week Dox, $44 \pm 10 \%$; and mutant +3 week Dox, $44 \pm 19 \%$. Control: $n=10$; mutant: $n=10$; control +3 week Dox: $n=7$; and mutant +3 week Dox: $n=8 .{ }^{*} p<0.05 .{ }^{* *} p<0.001$. 
cuitry to show that the absence of $\beta$-secretase, which cleaves APP to generate $\mathrm{A} \beta$, disrupts axonal guidance of OSNs in the $\mathrm{OB}$ (Rajapaksha et al., 2011; Cao et al., 2012a). Similarly, overexpression of $\mathrm{A} \beta$ is also found to alter axonal targeting of OSNs, and olfactory dysfunction is observed in 3- to 5-month-old animals (Cao et al., 2012b). To better understand the role of hAPP in neurodegeneration, we selectively expressed it at high levels in distinct subsets of OSNs (either mature or immature populations). We found that hAPP expression caused large-scale OSN apoptosis very rapidly by 3 weeks of age and was initiated primarily through a cell-autonomous mechanism (Cheng et al., 2011b). In the current study, we further showed that this widespread neurodegeneration produced broad and severe disruption of the $\mathrm{OB}$ circuitry at both anatomical and functional levels, as well as impaired olfactory behavior. All of these changes again occurred as early as 3 weeks of age. Although both olfactory sensory neuron loss (Talamo et al., 1989) and early olfactory dysfunction have been observed in AD patients (Bacon et al., 1998; Hawkes, 2003; Doty, 2009), the relation between the two is still unclear. Our data here support the notion that OSNs are very sensitive to elevated hAPP levels and that olfactory sensory neuron loss correlated directly with deficits in olfactory performance. Together, these studies emphasize the important link between olfactory dysfunction and $\mathrm{AD}$, whereas we further present a unique fastdeveloping and measurable model to study hAPP-induced neurodegeneration using olfactory circuitry. Although our results cannot currently distinguish hAPP-induced neurodegeneration from other forms of induced neurotoxicity, we believe that a better understanding of the APP signaling pathways will help to reveal the mechanistic basis of hAPP-induced apoptosis and possibly lead to new therapeutic strategies.

Recovery from injury or disease is a daunting challenge for the nervous system. During development, injury can induce a rerouting of neural connections with the resulting efficacy generally correlating to how well the altered pathways re-create the original circuit (Finlay et al., 1979; Gramsbergen and IjkemaPaassen, 1982; Willson et al., 2007). In the olfactory system, studies have used direct lesions or genetic ablation to disrupt OSN function and test restoration (Harding and Wright, 1979; Hurtt et al., 1988; Yee and Costanzo, 1995; Youngentob et al., 1997; Schwob et al., 1999; Costanzo, 2000; Gogos et al., 2000; Schwob and Youngentob, 2001; John and Key, 2003; Iwema et al., 2004; Youngentob and Schwob, 2006; Cheng et al., 2011a). Findings have varied with different lesion models reporting different levels of circuit restoration, but the clear structural framework of the olfactory system consistently provides a means for comprehensive assessment. This organizational advantage would also prove beneficial in recovery experiments that use $\mathrm{AD}$ models. For example, one study reversibly expressed hAPP in CaMKII-positive neurons that are broadly distributed throughout the brain, and showed that hyperactivity, a phenotype observed in mutant animals, was partially reversed by 1 month of transgene suppression (Jankowsky et al., 2005b). Unfortunately, because of the areas affected by the mutation, the changes in the underlying circuitry remain undefined. Thus, we sought to establish a measure of recovery that included anatomical circuitry, physiological function, and behavior using the olfactory system to compare them directly.

Using OMP-hAPP mice, we showed that glomerular anatomy and function could be readily disrupted and restored by increasing and decreasing hAPP levels in OSNs, respectively. To assess the behavioral consequences of these circuit changes, we used two olfactory assays: one relatively simple, a buried-food assay, and the other more challenging, using a single monomolecular odor in an avoidance assay. Our findings clearly showed that, within 1 week of Dox administration, mutant animals returned to control level performance in the buried-food assay, despite only partial restoration of glomerular circuitry as determined by anatomical and functional imaging measures. By comparison, recovery in the more difficult avoidance assay was gradual, requiring more time, and still not complete after 3 weeks of Dox administration, but showed that performance correlated with the degree of circuit restoration. The basis for the more rapid recovery in the buriedfood assay is unclear, but may be linked to odorant complexity because food odor is a mixture and thus may activate more glomeruli than the monomolecular odorant iVA. Another factor may be odorant concentration because the buried food test was always done with a whole cookie, whereas the avoidance assay used a range of iVA concentrations, with the lowest dilution not even discernible to control animals. Nonetheless, both assays highlighted the strong link between circuitry and function in the olfactory system, suggesting that behavioral assessment could serve as an indirect measure of anatomical organization, providing a glimpse into the state of circuitry. Importantly, the swift reversal of both circuit and behavioral deficits further supports a cellautonomous initiation of hAPP toxicity (Wirths et al., 2004; Ghosal et al., 2009; Cheng et al., 2011b) because extracellular amyloid deposits are shown to persist up to 6 months in vivo after hAPP expression is turned off (Jankowsky et al., 2005a).

Transgenic mice have proven to be an important tool for studying the efficacy of potential AD therapies within intact animals. Many studies have targeted APP metabolism, as a means of intervention, including both active (Schenk et al., 1999; Janus et al., 2000; Morgan et al., 2000; Lavie et al., 2004; Jensen et al., 2005) and passive (Dodart et al., 2002; Kotilinek et al., 2002; Lee et al., 2006) immunotherapy, use of secretase inhibitors (De Strooper et al., 2010; Fukumoto et al., 2010; Chang et al., 2011), efforts to enhance clearance of $\beta$-amyloid (Lim et al., 2000; Heneka et al., 2005; Zelcer et al., 2007; Wesson et al., 2011; Cramer et al., 2012), and also improvement of autophagic-lysosomal proteolytic function (Butler et al., 2011; Majumder et al., 2011; Yang et al., 2011). Although some evidence does support that a reduction of amyloid burden can ameliorate learning and memory deficits (Janus et al., 2000; Morgan et al., 2000; Lavie et al., 2004; Jensen et al., 2005), it is unclear whether the improvement in performance correlates with changes in underlying circuitry. Moreover, ADlike pathology usually requires many months to develop, and neuronal loss is rarely observed in most cortical or hippocampalbased models. Here, we propose that our olfactory-based AD model with its rapid degeneration and recovery could serve in complement to other models for studies of $\mathrm{AD}$-related processes in central circuits as well as for screening or testing the efficacy of potential therapeutics.

Early detection of $\mathrm{AD}$ has been proposed to be a critical factor in combating this devastating disease (Clark et al., 2008). A key factor that is changing disease diagnosis and therapy development is the insight that pathological changes underlying the brain degeneration and cognitive loss of patients begin at least 10-20 years before dementia onset (Holtzman et al., 2011). The development of biomarkers to detect neuropathology associated with early-stage AD will allow clinicians to successfully identify patients and initiate disease-modifying treatment much earlier in the pathological process, which will likely maximize treatment efficacy. Unfortunately, it is precisely at this stage that the clinical diagnosis is most difficult. Recently, the possibility of using olfaction as a biomarker for $\mathrm{AD}$ has been explored in both patients 
(Shaw et al., 2011; Schofield et al., 2012) and animal models (Wesson et al., 2010; Kameshima et al., 2012). Our current data using an $\mathrm{AD}$ model that is specifically olfactory-based, indicate that olfactory behavior can indeed provide effective insight into the circuit organization of the brain. Thus, we propose that olfactory function can serve as a biomarker to both track neurodegeneration and determine the efficacy of potential treatments, while this unique model provides a comprehensive platform to study hAPP-induced disruption and repair within a precisely defined in vivo network.

\section{References}

Arnold SE, Lee EB, Moberg PJ, Stutzbach L, Kazi H, Han LY, Lee VM, Trojanowski JQ (2010) Olfactory epithelium amyloid-beta and paired helical filament-tau pathology in Alzheimer disease. Ann Neurol 67:462-469. CrossRef Medline

Ashe KH, Zahs KR (2010) Probing the biology of Alzheimer's disease in mice. Neuron 66:631-645. CrossRef Medline

Axel R (1995) The molecular logic of smell. Sci Am 273:154-159. CrossRef Medline

Bacon AW, Bondi MW, Salmon DP, Murphy C (1998) Very early changes in olfactory functioning due to Alzheimer's disease and the role of apolipoprotein E in olfaction. Ann N Y Acad Sci 855:723-731. CrossRef Medline

Belluscio L, Katz LC (2001) Symmetry, stereotypy, and topography of odorant representations in mouse olfactory bulbs. J Neurosci 21:2113-2122. Medline

Bozza T, McGann JP, Mombaerts P, Wachowiak M (2004) In vivo imaging of neuronal activity by targeted expression of a genetically encoded probe in the mouse. Neuron 42:9-21. CrossRef Medline

Butler D, Hwang J, Estick C, Nishiyama A, Kumar SS, Baveghems C, YoungOxendine HB, Wisniewski ML, Charalambides A, Bahr BA (2011) Protective effects of positive lysosomal modulation in Alzheimer's disease transgenic mouse models. PLoS One 6:e20501. CrossRef Medline

Callaway EM (2002) Cell type specificity of local cortical connections. J Neurocytol 31:231-237. CrossRef Medline

Calof AL, Hagiwara N, Holcomb JD, Mumm JS, Shou J (1996) Neurogenesis and cell death in olfactory epithelium. J Neurobiol 30:67-81. CrossRef Medline

Cao L, Rickenbacher GT, Rodriguez S, Moulia TW, Albers MW (2012a) The precision of axon targeting of mouse olfactory sensory neurons requires the BACE1 protease. Sci Rep 2:231. CrossRef Medline

Cao L, Schrank BR, Rodriguez S, Benz EG, Moulia TW, Rickenbacher GT, Gomez AC, Levites Y, Edwards SR, Golde TE, Hyman BT, Barnea G, Albers MW (2012b) Abeta alters the connectivity of olfactory neurons in the absence of amyloid plaques in vivo. Nat Commun 3:1009. CrossRef Medline

Chang WP, Huang X, Downs D, Cirrito JR, Koelsch G, Holtzman DM, Ghosh AK, Tang J (2011) Beta-secretase inhibitor GRL-8234 rescues agerelated cognitive decline in APP transgenic mice. FASEB J 25:775-784. CrossRef Medline

Cheng K, Bai L, Belluscio L (2011a) Fas-associated factor 1 as a regulator of olfactory axon guidance. J Neurosci 31:11905-11913. CrossRef Medline

Cheng N, Cai H, Belluscio L (2011b) In vivo olfactory model of APPinduced neurodegeneration reveals a reversible cell-autonomous function. J Neurosci 31:13699-13704. CrossRef Medline

Clark CM, Davatzikos C, Borthakur A, Newberg A, Leight S, Lee VM, Trojanowski JQ (2008) Biomarkers for early detection of Alzheimer pathology. Neurosignals 16:11-18. CrossRef Medline

Costanzo RM (2000) Rewiring the olfactory bulb: changes in odor maps following recovery from nerve transection. Chem Senses 25:199-205. CrossRef Medline

Cowan CM, Roskams AJ (2002) Apoptosis in the mature and developing olfactory neuroepithelium. Microsc Res Tech 58:204-215. CrossRef Medline

Cramer PE, Cirrito JR, Wesson DW, Lee CY, Karlo JC, Zinn AE, Casali BT, Restivo JL, Goebel WD, James MJ, Brunden KR, Wilson DA, Landreth GE (2012) ApoE-directed therapeutics rapidly clear beta-amyloid and reverse deficits in AD mouse models. Science 335:1503-1506. CrossRef Medline

Cummings DM, Belluscio L (2008) Charting plasticity in the regenerating maps of the mammalian olfactory bulb. Neuroscientist 14:251-263. CrossRef Medline

Cummings DM, Belluscio L (2010) Continuous neural plasticity in the olfactory intrabulbar circuitry. J Neurosci 30:9172-9180. CrossRef Medline

De Strooper B, Vassar R, Golde T (2010) The secretases: enzymes with therapeutic potential in Alzheimer disease. Nat Rev Neurol 6:99-107. CrossRef Medline

Dodart JC, Bales KR, Gannon KS, Greene SJ, DeMattos RB, Mathis C, DeLong CA, Wu S, Wu X, Holtzman DM, Paul SM (2002) Immunization reverses memory deficits without reducing brain Abeta burden in Alzheimer's disease model. Nat Neurosci 5:452-457. CrossRef Medline

Doty RL (2009) The olfactory system and its disorders. Semin Neurol 29: 74-81. CrossRef Medline

Farbman AI (1990) Olfactory neurogenesis: genetic or environmental controls? Trends Neurosci 13:362-365. CrossRef Medline

Finlay BL, Wilson KG, Schneider GE (1979) Anomalous ipsilateral retinotectal projections in Syrian hamsters with early lesions: topography and functional capacity. J Comp Neurol 183:721-740. CrossRef Medline

Fukumoto H, Takahashi H, Tarui N, Matsui J, Tomita T, Hirode M, Sagayama M, Maeda R, Kawamoto M, Hirai K, Terauchi J, Sakura Y, Kakihana M, Kato K, Iwatsubo T, Miyamoto M (2010) A noncompetitive BACE1 inhibitor TAK-070 ameliorates Abeta pathology and behavioral deficits in a mouse model of Alzheimer's disease. J Neurosci 30:11157-11166. CrossRef Medline

Gabellec MM, Panzanelli P, Sassoè-Pognetto M, Lledo PM (2007) Synapsespecific localization of vesicular glutamate transporters in the rat olfactory bulb. Eur J Neurosci 25:1373-1383. CrossRef Medline

Ghosal K, Vogt DL, Liang M, Shen Y, Lamb BT, Pimplikar SW (2009) Alzheimer's disease-like pathological features in transgenic mice expressing the APP intracellular domain. Proc Natl Acad Sci U S A 106:18367-18372. CrossRef Medline

Gogos JA, Osborne J, Nemes A, Mendelsohn M, Axel R (2000) Genetic ablation and restoration of the olfactory topographic map. Cell 103: 609-620. CrossRef Medline

Gossen M, Bujard H (1992) Tight control of gene expression in mammalian cells by tetracycline-responsive promoters. Proc Natl Acad Sci U S A 89: 5547-5551. CrossRef Medline

Gramsbergen A, Ijkema-Paassen J (1982) CNS plasticity after hemicerebellectomy in the young rat: quantitative relations between aberrant and normal cerebello-rubral projections. Neurosci Lett 33:129-134. CrossRef Medline

Griff IC, Reed RR (1995) The genetic basis for specific anosmia to isovaleric acid in the mouse. Cell 83:407-414. CrossRef Medline

Harding JW, Wright JW (1979) Reversible effects of olfactory nerve section on behavior and biochemistry in mice. Brain Res Bull 4:17-22. CrossRef Medline

Hardy J, Selkoe DJ (2002) The amyloid hypothesis of Alzheimer's disease: progress and problems on the road to therapeutics. Science 297:353-356. CrossRef Medline

Hartman BK, Margolis FL (1975) Immunofluorescence localization of the olfactory marker protein. Brain Res 96:176-180. CrossRef Medline

Hawkes C (2003) Olfaction in neurodegenerative disorder. Mov Disord 18: 364-372. CrossRef Medline

Heneka MT, Sastre M, Dumitrescu-Ozimek L, Hanke A, Dewachter I, Kuiperi C, O’Banion K, Klockgether T, Van Leuven F, Landreth GE (2005) Acute treatment with the PPARgamma agonist pioglitazone and ibuprofen reduces glial inflammation and Abeta1-42 levels in APPV717I transgenic mice. Brain 128:1442-1453. CrossRef Medline

Holtzman DM, Morris JC, Goate AM (2011) Alzheimer's disease: the challenge of the second century. Sci Transl Med 3:77sr71. CrossRef Medline

Hurtt ME, Thomas DA, Working PK, Monticello TM, Morgan KT (1988) Degeneration and regeneration of the olfactory epithelium following inhalation exposure to methyl bromide: pathology, cell kinetics, and olfactory function. Toxicol Appl Pharmacol 94:311-328. CrossRef Medline

Iwema CL, Fang H, Kurtz DB, Youngentob SL, Schwob JE (2004) Odorant receptor expression patterns are restored in lesion-recovered rat olfactory epithelium. J Neurosci 24:356-369. CrossRef Medline

Jankowsky JL, Slunt HH, Gonzales V, Savonenko AV, Wen JC, Jenkins NA, Copeland NG, Younkin LH, Lester HA, Younkin SG, Borchelt DR (2005a) Persistent amyloidosis following suppression of Abeta production in a transgenic model of Alzheimer disease. PLoS Med 2:e355. CrossRef Medline

Jankowsky JL, Slunt HH, Gonzales V, Savonenko AV, Wen JC, Jenkins NA, 
Copeland NG, Younkin LH, Lester HA, Younkin SG, Borchelt DR (2005b) Persistent amyloidosis following suppression of Abeta production in a transgenic model of Alzheimer disease. PLoS Med 2:e355. CrossRef

Janus C, Pearson J, McLaurin J, Mathews PM, Jiang Y, Schmidt SD, Chishti MA, Horne P, Heslin D, French J, Mount HT, Nixon RA, Mercken M, Bergeron C, Fraser PE, St George-Hyslop P, Westaway D (2000) A beta peptide immunization reduces behavioural impairment and plaques in a model of Alzheimer's disease. Nature 408:979-982. CrossRef Medline

Jensen MT, Mottin MD, Cracchiolo JR, Leighty RE, Arendash GW (2005) Lifelong immunization with human beta-amyloid (1-42) protects Alzheimer's transgenic mice against cognitive impairment throughout aging. Neuroscience 130:667-684. CrossRef Medline

John JA, Key B (2003) Axon mis-targeting in the olfactory bulb during regeneration of olfactory neuroepithelium. Chem Senses 28:773-779. CrossRef Medline

Kameshima N, Nanjou T, Fukuhara T, Yanagisawa D, Tooyama I (2012) Correlation of Abeta deposition in the nasal cavity with the formation of senile plaques in the brain of a transgenic mouse model of Alzheimer's disease. Neurosci Lett 513:166-169. CrossRef Medline

Kotilinek LA, Bacskai B, Westerman M, Kawarabayashi T, Younkin L, Hyman BT, Younkin S, Ashe KH (2002) Reversible memory loss in a mouse transgenic model of Alzheimer's disease. J Neurosci 22:6331-6335. Medline

LaFerla FM, Green KN (2012) Animal models of Alzheimer disease. Cold Spring Harb Perspect Med 2:11. CrossRef Medline

Lavie V, Becker M, Cohen-Kupiec R, Yacoby I, Koppel R, Wedenig M, Hutter-Paier B, Solomon B (2004) EFRH-phage immunization of Alzheimer's disease animal model improves behavioral performance in Morris water maze trials. J Mol Neurosci 24:105-113. CrossRef Medline

Lee EB, Leng LZ, Zhang B, Kwong L, Trojanowski JQ, Abel T, Lee VM (2006) Targeting amyloid-beta peptide (Abeta) oligomers by passive immunization with a conformation-selective monoclonal antibody improves learning and memory in Abeta precursor protein (APP) transgenic mice. J Biol Chem 281:4292-4299. CrossRef Medline

Lewandoski M (2001) Conditional control of gene expression in the mouse. Nat Rev Genet 2:743-755. CrossRef Medline

Lim GP, Yang F, Chu T, Chen P, Beech W, Teter B, Tran T, Ubeda O, Ashe KH, Frautschy SA, Cole GM (2000) Ibuprofen suppresses plaque pathology and inflammation in a mouse model for Alzheimer's disease. J Neurosci 20:5709-5714. Medline

Majumder S, Richardson A, Strong R, Oddo S (2011) Inducing autophagy by rapamycin before, but not after, the formation of plaques and tangles ameliorates cognitive deficits. PLoS One 6:e25416. CrossRef Medline

Mombaerts P (2006) Axonal wiring in the mouse olfactory system. Annu Rev Cell Dev Biol 22:713-737. CrossRef Medline

Mombaerts P, Wang F, Dulac C, Chao SK, Nemes A, Mendelsohn M, Edmondson J, Axel R (1996) Visualizing an olfactory sensory map. Cell 87:675-686. CrossRef Medline

Morgan D, Diamond DM, Gottschall PE, Ugen KE, Dickey C, Hardy J, Duff K, Jantzen P, DiCarlo G, Wilcock D, Connor K, Hatcher J, Hope C, Gordon M, Arendash GW (2000) A beta peptide vaccination prevents memory loss in an animal model of Alzheimer's disease. Nature 408:982-985. CrossRef Medline

Nguyen MQ, Zhou Z, Marks CA, Ryba NJ, Belluscio L (2007) Prominent roles for odorant receptor coding sequences in allelic exclusion. Cell 131: 1009-1017. CrossRef Medline

Palop JJ, Mucke L (2010) Amyloid-beta-induced neuronal dysfunction in Alzheimer's disease: from synapses toward neural networks. Nat Neurosci 13:812-818. CrossRef Medline

Pourtier L, Sicard G (1990) Comparison of the sensitivity of C57BL/6J and $\mathrm{AKR} / \mathrm{J}$ mice to airborne molecules of isovaleric acid and amyl acetate. Behav Genet 20:499-509. CrossRef Medline

Rajapaksha TW, Eimer WA, Bozza TC, Vassar R (2011) The Alzheimer's beta-secretase enzyme BACE1 is required for accurate axon guidance of olfactory sensory neurons and normal glomerulus formation in the olfactory bulb. Mol Neurodegener 6:88. CrossRef Medline

Schenk D, Barbour R, Dunn W, Gordon G, Grajeda H, Guido T, Hu K, Huang J, Johnson-Wood K, Khan K, Kholodenko D, Lee M, Liao Z, Lieberburg I,
Motter R, Mutter L, Soriano F, Shopp G, Vasquez N, Vandevert C, et al. (1999) Immunization with amyloid-beta attenuates Alzheimer-diseaselike pathology in the PDAPP mouse. Nature 400:173-177. CrossRef Medline

Schofield PW, Ebrahimi H, Jones AL, Bateman GA, Murray SR (2012) An olfactory "stress test" may detect preclinical Alzheimer's disease. BMC Neurol 12:24. CrossRef Medline

Schwob JE, Youngentob SL (2001) Reinnervation of the olfactory bulb and functional capacity after recovery from lesions of the olfactory epithelium. Chem Senses 26:732.

Schwob JE, Youngentob SL, Ring G, Iwema CL, Mezza RC (1999) Reinnervation of the rat olfactory bulb after methyl bromide-induced lesion: timing and extent of reinnervation. J Comp Neurol 412:439-457. CrossRef Medline

Shaw CA, Li Y, Wiszniewska J, Chasse S, Zaidi SN, Jin W, Dawson B, Wilhelmsen K, Lupski JR, Belmont JW, Doody RS, Szigeti K (2011) Olfactory copy number association with age at onset of Alzheimer disease. Neurology 76:1302-1309. CrossRef Medline

Stevens CF (1998) Neuronal diversity: too many cell types for comfort? Curr Biol 8:R708-R710.

Talamo BR, Rudel R, Kosik KS, Lee VM, Neff S, Adelman L, Kauer JS (1989) Pathological changes in olfactory neurons in patients with Alzheimer's disease. Nature 337:736-739. CrossRef Medline

Vassalli A, Rothman A, Feinstein P, Zapotocky M, Mombaerts P (2002) Minigenes impart odorant receptor-specific axon guidance in the olfactory bulb. Neuron 35:681-696. CrossRef Medline

Wesson DW, Levy E, Nixon RA, Wilson DA (2010) Olfactory dysfunction correlates with amyloid-beta burden in an Alzheimer's disease mouse model. J Neurosci 30:505-514. CrossRef Medline

Wesson DW, Borkowski AH, Landreth GE, Nixon RA, Levy E, Wilson DA (2011) Sensory network dysfunction, behavioral impairments, and their reversibility in an Alzheimer's beta-amyloidosis mouse model. J Neurosci 31:15962-15971. CrossRef Medline

Willson ML, Bower AJ, Sherrard RM (2007) Developmental neural plasticity and its cognitive benefits: olivocerebellar reinnervation compensates for spatial function in the cerebellum. Eur J Neurosci 25:1475-1483. CrossRef Medline

Wirths O, Multhaup G, Bayer TA (2004) A modified beta-amyloid hypothesis: intraneuronal accumulation of the beta-amyloid peptide: the first step of a fatal cascade. J Neurochem 91:513-520. CrossRef Medline

World Alzheimer Report (2012) Overcoming the stigma of dementia. London, UK: Alzheimer's Disease International.

Wysocki CJ, Whitney G, TuckerD (1977) Specific anosmia in the laboratory mouse. Behav Genet 7:171-188. CrossRef Medline

Yang DS, Stavrides P, Mohan PS, Kaushik S, Kumar A, Ohno M, Schmidt SD, Wesson D, Bandyopadhyay U, Jiang Y, Pawlik M, Peterhoff CM, Yang AJ, Wilson DA, St George-Hyslop P, Westaway D, Mathews PM, Levy E, Cuervo AM, Nixon RA (2011) Reversal of autophagy dysfunction in the TgCRND8 mouse model of Alzheimer's disease ameliorates amyloid pathologies and memory deficits. Brain 134:258-277. CrossRef Medline

Yang M, Crawley JN (2009) Simple behavioral assessment of mouse olfaction. Curr Protoc Neurosci Chapter 8:Unit 8 24. CrossRef Medline

Yee KK, Costanzo RM (1995) Restoration of olfactory mediated behavior after olfactory bulb deafferentation. Physiol Behav 58:959-968. CrossRef Medline

Youngentob SL, Schwob JE (2006) Odorant identification and quality perception following methyl bromide-induced lesions of the olfactory epithelium. Behav Neurosci 120:1346-1355. CrossRef Medline

Youngentob SL, Schwob JE, Sheehe PR, Youngentob LM (1997) Odorant threshold following methyl bromide-induced lesions of the olfactory epithelium. Physiol Behav 62:1241-1252. CrossRef Medline

Yu CR, Power J, Barnea G, O’Donnell S, Brown HE, Osborne J, Axel R, Gogos JA (2004) Spontaneous neural activity is required for the establishment and maintenance of the olfactory sensory map. Neuron 42:553-566. CrossRef Medline

Zelcer N, Khanlou N, Clare R, Jiang Q, Reed-Geaghan EG, Landreth GE, Vinters HV, Tontonoz P (2007) Attenuation of neuroinflammation and Alzheimer's disease pathology by liver x receptors. Proc Natl Acad Sci U S A 104:10601-10606. CrossRef Medline 